\title{
WUJUD PILIHAN KODE TUTUR PENDATANG DI LEMBAGA RUMAH QURAN, TANGERANG SELATAN
}

\author{
Ratna Dewi Kartikasari ${ }^{1}$, Avifa Choirunisa ${ }^{2}$ \\ Ratna.dewikartikasari@umj.ac.id ${ }^{1}$, Avifa.choirunisa@gmail.com² \\ Universitas Muhammadiyah Jakarta
}

\begin{abstract}
Abstrak
Pendatang di Lembaga Rumah Quran yang menggunakan keberagaman bahasa menggambarkan kecenderungan pemilihan bahasa pada bilingual juga multilingual. Terkait hal tersebut menyebabkan adanya pilihan kode yang digunakan oleh pendatang di Lembaga Rumah Quran. Tujuan dari penelitian ini adalah menemukan dan mendeskripsikan wujud pilihan kode tutur yang digunakan pendatang pada pergaulan di kota Tangerang Selatan. Dalam penelitian ini, peneliti menggunakan metode padan dengan teknik dasar pilah unsur penentu (PUP) dan teknik lanjutan teknik hubung banding membedakan (HBB). Penelitian ini menggunakan teknik pengumpulan data dengan teknik dasar sadap, teknik menyimak bebas, rekam, dan teknik pencatatan. Diketahui bahwa terdapat (1) tunggal bahasa yang meliputi: bahasa Indonesia nonformal, bahasa Jawa ngoko, bahasa Betawi, dan bahasa Palembang atau bahasa musi; (2) alih kode; dan (3) campur kode.
\end{abstract}

Kata kunci: alih kode, campur kode, sosiolinguistik.

\section{PENDAHULUAN}

Penggunaan bahasa dalam kelompok masyarakat sedang berkomunikasi, maka dapat disebut bahwa mereka menggunakan kode. Jika pembicara dapat menggunakan lebih dari satu bahasa, maka pembicara telah memiliki akses dua kode atau lebih karena besar kemungkinan pembicara sering atau terbiasa menggunakan bahasa-bahasa yang telah dikuasai pada saat berkomunikasi. Pemilihan bahasa dalam masyarakat dwibahasa atau multibahasa menjadi gejala yang sangat menarik untuk dikaji dari perspektif sosiolinguistik. Masyarakat bilingualisme atau multilingualisme dapat ditemukan dalam bidang apapun di dunia dan masyarakat di pandangan tersebut akan melihat situasi yang lain. Biasanya masyarakat multilingualisme adalah penduduk imigran atau kelompok masyarakat rendah. Dengan adanya perpindahan penduduk dari satu daerah ke daerah lainnya atau dari suatu negeri ke negeri lainnya, terjadi interaksi pada masyarakat pendatang dan masyarakat lokal. Dalam masyarakat bilingual atau multilingual, alih kode merupakan salah satu aspek ketergantungan bahasa. Artinya dalam masyarakat bilingual atau multilingual memungkinkan seorang penutur menggunakan berbagai kode dalam tindak tuturnya sesuai dengan situasi dan berbagai aspek yang melingkupinya.

Para pendatang yang tinggal di Rumah Quran berasal dari latar belakang daerah yang berbeda-beda. Daerah asal mereka yang berbeda bahasa dengan bahasa yang digunakan di masyarakat daerah Rumah Quran yang berada di kota Tangerang Selatan membuat mereka menjadi masyarakat tutur billingualisme. Pada lingkungan Rumah Quran masyarakat sekitar menggunakan bahasa Indonesia nonformal untuk berkomunikasi sehari-hari. Para pendatang menggunakan bahasa Indonesia saat pembelajaran Quran, sedangkan ketika sedang berkomunikasi dengan teman sebayanya mereka menggunakan bahasa daerah asal juga bahasa Indonesia nonformal. Ada yang menggunakan bahasa Jawa, bahasa Betawi atau bahasa Palembang. Kebanyakan dari mereka merupakan pendatang dari Palembang, jadi di dalam Rumah Quran lebih sering terdengar bahasa Palembang.

Dengan dilakukannya penelitian ini adalah untuk menemukan dan mendeskripsikan wujud pilihan kode tutur yang digunakan pendatang pada pergaulan di kota Tangerang Selatan. Objek penelitian ini adalah para pendatang (Jawa, Palembang, Betawi) di Rumah Quran, Tangerang Selatan. Dalam penelitian ini, peneliti menggunakan metode padan dengan teknik dasar pilah unsur penentu (PUP) dan teknik lanjutan teknik hubung banding membedakan (HBB). Penelitian ini menggunakan teknik pengumpulan data dengan teknik dasar sadap, teknik menyimak bebas, rekam, dan teknik pencatatan. 


\section{LANDASAN TEORI}

Sosiolinguistik menurut Muhammad dan Khaerunnisa (2019:2) merupakan gabungan dua disiplin ilmu yaitu sosiologi dan ilmiah. Sosiologi merupakan bagian dari kajian objektif dan ilmiah bagian dari manusia di dalam masyarakat, proses sosial yang terdapat pada masyarakat dan linguistik (ilmu yang mempelajari bahasa). Fashold dalam Muhammad dan Khaerunnisa (2019: 9) mengungkapkan bahwa dengan adanya pemilihan bahasa membuat sosiolinguistik dapat menjadi bidang studi. Bahasa tidak dapat dipisahkan dari masyarakat, begitu juga sebaliknya. Sekelompok orang atau masyarakat yang menggunakan bahasa dalam berkomunikasi maka dapat disebut sebagai masyarakat tutur. Fishman dalam Mutmainnah (2008: 24) berpendapat bahwa masyarakat tutur merupakan suatu masyarakat yang anggota-anggotanya setidaktidaknya mengenal satu variasi bahasa beserta norma-norma yang sesuai dengan penggunaannya.

Faktor-faktor yang menjadi penyebab terjadinya peristiwa tutur dalam komponen-komponen tutur menurut Dell Hymes dalam Putri (2017: 80), SPEAKING yaitu Setting and Scene (latar) yaitu tempat atau suasana bicara, Participants (peserta) yaitu pembicara, pendengar dan lawan bicara, Ends (hasil) yaitu tujuan bicara, Act (amanat) yaitu peristiwa ketika pembicara sedang berbicara, Key (cara) yaitu nada suara dan ragam bahasa yang digunakan oleh pembicara ketika sedang berbicara, Instrumentalities (sarana) yaitu alat untuk menyampaikan pembicaraan atau pendapat dari pembicara, Norma (norma) yaitu aturan dalam berbicara atau diskusi, Genres (jenis) yaitu jenis kegiatan berbicara atau diskusi. Menurut sudut pandang sosiolinguistik, penggunaan variasi kode bahasa dalam masyarakat dwibahasa atau multibahasa ialah menjadi gejala yang menarik untuk dikaji. Kode biasanya berbentuk variasi bahasa yang digunakan dalam masyarakat tutur ketika berkomunikasi. Sholihatin dalam Kholidah dan Haryadi (2017: 209) pilihan kode terletak pada konteks situasi yang digunakan dalam interaksi. Situasi yang dimaksud ialah latar sosial dan latar kultural.

Penggunaan sebuah kode dalam masyarakat dwibahasa atau multibahasa tentu tidak dapat dihindari untuk mengimbangi lawan tuturnya. Dalam peristiwa tersebut, masyarakat dwibahasa atau multibahasa harus mampu berganti kode sesuai dengan situasi dan kondisi agar lawan tutur dapat memahaminya. Menurut Rokhman dalam Mutmainnah (2008: 30) terdapat tiga kategori pemilihan bahasa yaitu, satu variasi dari bahasa yang sama. Contohnya, ketika penutur dwibahasa Jawa akan berbicara dengan orang lain. Kemudian, alih kode yaitu peralihan kode satu ke kode bahasa yang lainnya. Lalu yang terakhir, campur kode yaitu penggunaan satuan bahasa dari yang satu ke bahasa yang lainnya.

Menurut Munandar (2018: 2) Alih kode dan campur kode adalah suatu peristiwa yang sering terjadi pada tempat kegiatan rutinitas masyarakat yang di dalamnya mempertemukan orang-orang yang berasal dari daerah dan bahasa yang berbeda-beda. Masyarakat Jawa, Palembang atau Tangerang Selatan cenderung menggunakan bahasa daerah masing-masing sebagai bahasa komunikasi sehari-hari, namun di berbagai aktivitas mereka selain menggunakan bahasa daerah, mereka juga menggunakan bahasa Indonesia. Penggunaan bahasa seperti hal tersebut, sangat memungkinkan untuk memunculkan peristiwa alih kode dan campur kode.

\section{HASIL PENELITIAN DAN PEMBAHASAN}

Pendatang di Lembaga Rumah Quran yang menggunakan keberagaman bahasa menggambarkan kecenderungan pemilihan bahasa pada bilingual juga multilingual. Terkait hal tersebut menyebabkan adanya pilihan kode yang digunakan oleh pendatang di Lembaga Rumah Quran. Diketahui bahwa bahasa yang digunakan oleh pendatang di Rumah Quran, Tangerang Selatan terdapat (1) tunggal bahasa yang meliputi: bahasa Indonesia nonformal, bahasa Jawa ngoko, bahasa Betawi, dan bahasa Palembang atau bahasa musi; (2) alih kode; dan (3) campur kode.

1) Tunggal bahasa. Tunggal bahasa digunakan oleh pendatang di Rumah Quran ialah bahasa Indonesia nonformal, bahasa Jawa, bahasa Betawi dan bahasa Palembang. Bahasa Indonesia nonformal digunakan dalam diskusi sesama pendatang dengan pendatang dari daerah lain atau masyarakat sekitar Rumah Quran, bahasa Jawa digunakan oleh sesama pendatang dari daerah Jawa, bahasa Betawi digunakan oleh pendatang daerah Jakarta juga masyarakat tutur sekitar Rumah Quran karena bahasa Betawi tidak jauh berbeda dengan bahasa Indonesia, dan bahasa Palembang digunakan oleh sesama pendatang dari daerah Palembang. 
a) Bahasa Indonesia nonformal. Bahasa Indonesia ragam nonformal biasanya digunakan dalam pembicaraan santai atau situasi yang tidak resmi. Hal ini juga digunakan oleh pendatang di Rumah Quran, Tangerang Selatan. Mereka menggunakan bahasa Indonesia nonformal sebagai bahasa komunikasi sehari-hari mereka ketika sedang berkumpul bersama agar menjadi lebih akrab dan mudah dipahami pendengar.

(1) Konteks: percakapan pendatang Palembang (P1) dengan pendatang Jawa (P2) dan pendatang Betawi (P3) yang sedang berdiskusi tentang akan memasak apa mereka hari ini untuk segera pergi berbelanja bahan masakan yang akan dimasak.

P1: Hari ini aku mau pergi ke Pasar, kalian mau makan apa? nanti aku belikan bahan makanannya.

\section{P2: Kentang balado, gimana?}

P3: Iya, boleh. Kentang balado sama tumis kangkung ya.

Peristiwa tutur (1) terjadi di dalam kamar Rumah Quran. Pendatang Palembang (P1) akan pergi ke Pasar terdekat untuk membeli bahan makanan yang akan dimasak. Pendatang Jawa (P2) memberikan saran makanan yang akan dibeli bahan makananannya juga yang akan dimasak nanti. Pendatang Betawi (P3) menambahkan saran makanan yang akan dibeli juga dimasak. Penggalan tuturan tersebut merupakan tunggal bahasa yang berupa bahasa Indonesia nonformal. Bahasa Indonesia ragam nonformal dapat dilihat dalam kalimat yang diucapkan P1 pada kata "Aku" dan "mau". Selain itu, P2 juga menggunakan bahasa Indonesia nonformal pada kata "gimana?". Kemudian, P3 juga menggunakan bahasa Indonesia ragam nonformal, dapat dilihat pada kata "sama" yang memiliki arti "dan".

b) Bahasa Jawa. Bahasa Jawa digunakan oleh pendatang dari daerah Jawa dalam situasi atau keadaan santai. Biasanya bahasa Jawa ini digunakan oleh pendatang Jawa dengan sesama pendatang Jawa atau pendatang yang mahir dalam berbahasa Jawa. Berikut ini adalah penggalan percakapan bahasa Jawa oleh pendatang Jawa dengan pendatang lain.

(2) Konteks: percakapan pendatang Jawa (P1) dengan pendatang Palembang (P2) yang sedang berdiskusi tentang kegiatan mereka setelah hafalan Al quran.

P1: Mbak, sauwes iki kita duwe kegiatan opo? (Kak, setelah ini, kita ada kegiatan apa?)

P2: kegiatan murojaah bebarengan koyo dhewee (kegiatan murojaah bersama sepertinya)

P1: kita ora obah yo? (kita tidak pindah tempat ya?)

P2: iyo. Neng kene nanti awan (ya. Tetap di sini hingga nanti siang)

Peristiwa tutur (2) terjadi di ruang hafalan Rumah Quran. Pendatang Jawa (P1) bertanya tentang kegiatan yang akan dilakukan oleh mereka setelah kegiatan hafalan Al quran. Pendatang Palembang (P2) menjawab pertanyaan P1. Penggalan tuturan tersebut merupakan tunggal bahasa yang berupa bahasa Jawa. Bahasa Jawa dapat dilihat dalam tuturan P1 kalimat pertama yaitu, kata sapaan "mbak", "sauwes iki", "duwe", dan "opo". Lalu, pada jawaban kedua, "ora" dan "obah. Selanjutnya, pada tuturan P2 yaitu, "bebarengan", "koyo" dan "wong dhewee". Selanjutnya pada kalimat kedua, "neng kene" dan "awan".

c) Bahasa Palembang. Bahasa Palembang digunakan pendatang dari daerah Palembang dalam situasi atau keadaan santai. Biasanya bahasa Palembang terucap atau terujar oleh mereka ketika dalam suatu 
kondisi tertentu (dilakukan tanpa sengaja). Berikut ini merupakan contoh percakapan bahasa Palembang oleh pendatang Palembang.

(3) Konteks: percakapan pendatang Jawa (P1) dengan pendatang Palembang (P2) yang sedang berdiskusi tentang kunjungan keluarga dari keluarga salah satu pendatang.

P1: tadi keluargo awak tibo yo? (Tadi keluargamu datang ya?)

P2: iyo. Kamu galo dienjuk makanan dari wong tuoku. (Ya. Kalian dibawakan makanan dari orang tuaku)

P1: aih. Aku nak cobo cicipi. Mo kasih yo. (Wah. Aku mau coba. Terima kasih ya)

Peristiwa tutur (3) terjadi di ruang tamu Rumah Quran. Pendatang Jawa (P1) bertanya tentang kedatangan keluarga pendatang Palembang. Pendatang Palembang (P2) menjawab pertanyaan P1 juga memberikan makanan oleh-oleh dari orang tuanya. Penggalan tuturan tersebut merupakan tunggal bahasa yang berupa bahasa Palembang. Bahasa Palembang dapat dilihat dalam tuturan P1 kalimat pertama yaitu, "keluargo", "awak", dan "tibo". Lalu, pada jawaban kedua, "nak cobo", "cicipi”" dan "mo kasih". Selanjutnya, pada tuturan P2 yaitu, "galo", "dienjuk" dan "wong tuaku".

2) Alih Kode. Alih kode merupakan peralihan kode satu ke kode bahasa yang lainnya. Dalam peristiwa tutur pendatang di Rumah Quran, alih kode yang terjadi yaitu (1) alih kode dari bahasa Indonesia ke bahasa Jawa, (2) alih kode dari bahasa Jawa ke bahasa Indonesia, (3) alih kode bahasa Indonesia ke bahasa Palembang, (4) alih kode dari bahasa Palembang ke Bahasa Indonesia. Wujud pilihan bahasa alih kode terdapat pada penggalan tuturan berikut ini.

(4) Konteks: pendatang Palembang (P1) berdiskusi dengan pendatang Jawa (P2) tentang hafalan Al quran mereka.

P1: Kak Syifa, tadi kamu hafalan ayat berapa?

P2: Ayat 5 sampai ayat 8, Sar.

P1: Pancen angel banget kak, ayat 8 (susah sekali ya kak, ayat 8 dihafalkannya)

P2: Wah, iyo. Kulo moco bola-bali supoyo tak ngapalke (wah, iya. Aku sampai berulang kali membacanya agar bisa hafal)

Peristiwa tutur (4) terjadi di ruang hafalan Rumah Quran. Pendatang Palembang (P1) bertanya tentang hafalan lawan tuturnya. Pendatang Jawa (P2) menjawab pertanyaan P1. Penggalan tuturan tersebut merupakan alih kode dari bahasa Indonesia ke bahasa Jawa. Alih kode dapat dilihat dalam kata "pancen angel" yang diucapkan oleh P1. Kemudian, P2 menjawab tuturan P1 dengan menggunakan bahasa Jawa, "kulo moco bola-bali supoyo tak ngapalke".

(5) Konteks: pendatang Jawa (P1) sedang berbicara kepada lawan tuturnya yaitu pendatang Palembang (P2) untuk mengajaknya pergi ke Pasar.

P1: Ngapoi kau di sini? (sedang apa kau di sini?)

P2: Ndak ngapoi, aku jingok bahan makanan nyiso bae (tidak apa-apa, aku hanya melihat bahan makanan yang masih sisa)

P1: oh begitu, nanti sore aku mau pergi ke Pasar, kamu mau ikut? 
P2: boleh.

Peristiwa tutur (5) terjadi di dapur Rumah Quran. Pendatang Jawa (P1) bertanya kepada pendatang Palembang (P2) sedang melakukan apa. Pendatang Palembang (P2) menjawab pertanyaan pendatang Jawa (P1). Penggalan tuturan tersebut merupakan alih kode dari bahasa Palembang ke bahasa Indonesia. Alih kode dapat dilihat pada tuturan P1 "ngapoi". P2 menjawab pertanyaan P1 juga menggunakan bahasa Palembang, "ndak ngapoi, aku jingok bahan makanan nyiso bae". Namun, karena keterbatasan bahasa P1, kemudian P1 membalas tuturan P2 dengan menggunakan bahasa Indonesia.

3) Campur Kode. Campur kode merupakan penggunaan satuan bahasa dari yang satu ke bahasa yang lainnya. Peristiwa tutur ini muncul ketika pendatang Jawa sedang berbicara dengan pendatang lain. Campur kode yang muncul ialah bahasa daerah Jawa dan bahasa Indonesia. Berikut ini merupakan contoh dari penggalan percakapan campur kode.

(6) Konteks: pendatang Jawa (P1) ingin mengajak pendatang Palembang (P2) untuk pergi olahraga besok pagi.

P1: mbak, besok kita pergi sepedahan yuk

P2: besok jam piro?

Peristiwa tutur (5) terjadi di kamar Rumah Quran. Pendatang Jawa (P1) mengajak pendatang Palembang (P2) untuk berlohraga bersama. Pendatang Palembang (P2) menjawab ajakan pendatang Jawa (P1) dengan pertanyaan, mereka akan pergi olahraga pukul berapa. Penggalan tuturan tersebut merupakan campur kode bahasa Jawa dengan bahasa Indonesia. Campur kode dapat dilihat pada kata sapaan "mbak" oleh tuturan P1, dan P2 dengan kata "jam piro".

\section{SIMPULAN}

Berdasarkan hasil dari penelitian yang telah dilakukan oleh peneliti pada pendatang di Rumah Quran, Tangerang Selatan. Wujud pilihan kode tutur pendatang di Lembaga Rumah Quran, Tangerang Selatan memiliki (1) tunggal bahasa yang meliputi: bahasa Indonesia nonformal, bahasa Jawa ngoko, bahasa Betawi, dan bahasa Palembang atau bahasa musi; (2) alih kode; dan (3) campur kode. Hal ini disebabkan pendatang berasal dari latar belakang daerah yang berbeda-beda. Pendatang di Lembaga Rumah Quran yang menggunakan keberagaman bahasa menggambarkan kecenderungan pemilihan bahasa pada bilingual juga multilingual. Terkait hal tersebut menyebabkan adanya pilihan kode.

\section{DAFTAR PUSTAKA}

Kholidah, Umi dan Haryadi. 2017. Wujud Pilihan Kode Tutur Mahasiswa Aceh pada Ranah Pergaulan di Semarang. Seloka, Vol.6 No.2. Agustus 2017.

Muhammad, Sukardi dan Khaerunnisa. 2019. Sosiolinguistik (Teori dan Praktik). Karanganyar: CV Al Chalief.

Munandar, Aris. 2018. Alih Kode dan Campur Kode dalam Interaksi Masyarakat Terminal Mallengkeri, Kota Makasssar.

Mutmainnah, Yulia. 2008. Pemilihan Kode dalam Masyarakat Dwibahasa: Kajian Sosiolinguistik Pada Masyarakat Jawa di Kota Bontang, Kalimantan Timur.

Putri, Nike Aditya. 2017. Pilihan Kode dalam Masyarakat Dwibahasa: Kajian Sosiolinguistik Pada SMPSMA Semesta Billingual Boarding School, Semarang. Riksa Bahasa, Vol.3 No.1. Maret 2017. 